\title{
Coping Strategies for Adverse Effects of Antiretroviral Therapy among Adult HIV Patients Attending University of Gondar Referral Hospital, Gondar, Northwest Ethiopia: A Cross-Sectional Study
}

\author{
Yitayih Kefale Gelaw $\mathbb{D}^{1},{ }^{1}$ Boressa Adugna $\mathbb{D}^{2},{ }^{2}$ Adino Tesfahun Tsegaye $\mathbb{D}{ }^{3}$ \\ Tadesse Melaku, ${ }^{2}$ and Belayneh Kefale ${ }^{4}{ }^{4}$ \\ ${ }^{1}$ Department of Clinical Pharmacy, Enat Hospital, Amhara Region, North Shewa, Alem Ketema, Ethiopia \\ ${ }^{2}$ Department of Clinical Pharmacy, School of Pharmacy, College of Medicine and Health Sciences, University of Gondar, \\ Gondar, Ethiopia \\ ${ }^{3}$ Department of Epidemiology and Biostatistics, School of Public Health, College of Medicine and Health Sciences, University of Gondar, \\ Gondar, Ethiopia \\ ${ }^{4}$ Department of Pharmacy, College of Medicine and Health Science, Ambo University, P.O. Box 19, Ambo, Ethiopia
}

Correspondence should be addressed to Yitayih Kefale Gelaw; yitayihkefale@yahoo.com

Received 8 February 2018; Revised 30 September 2018; Accepted 19 November 2018; Published 2 December 2018

Academic Editor: Brian W. Pence

Copyright (C) 2018 Yitayih Kefale Gelaw et al. This is an open access article distributed under the Creative Commons Attribution License, which permits unrestricted use, distribution, and reproduction in any medium, provided the original work is properly cited.

Background. Adverse effects from antiretroviral therapy (ART) have an impact on quality of life and medication adherence. There is no clear understanding of how people manage the adverse effects of ART. The individual taking medications which cause serious adverse effects may choose to stop or reduce the medications to relieve the adverse effects. Hence, this study was aimed at assessing coping strategies for adverse effects of ART among adult human immunodeficiency virus (HIV) patients. Methods. A cross-sectional study was conducted at HIV clinic of University of Gondar Referral Hospital (UoGRH). A total of 394 study participants were recruited by systematic random sampling. Data were collected through interviewing patients. Data were entered to Epi-Info 3.5.4 and analyzed using SPSS-20.0. Descriptive statistics were used to summarize patient's sociodemographic data and the adverse effects of their ART regimen. Binary and multivariate logistic regressions were used to investigate the potential predictors of nonadherence coping strategies. Results. The majorities of study participants were females (66\%) and aged between 35 and 44 years (38.1\%). The major adverse effects reported by the participants were headache (48.2\%) followed by fatigability (18\%) and loss of appetite (17.5\%). Coping strategies used by HIV patients for adverse effect of ART were positive emotion coping strategy (91.1\%), social support seeking $(76.6 \%)$, taking other medications (76.6\%), information seeking $(48.7 \%)$, and nonadherence (35.5\%). Younger age (AOR = $29.54,95 \% \mathrm{CI}=2.49-35.25, \mathrm{p}=0.007)$, low level of education ( $\mathrm{AOR}=5.70,95 \% \mathrm{CI}=2.16-15.05, \mathrm{p}<0.001)$, and living far from the health institution ( $\mathrm{AOR}=2.68,95 \% \mathrm{CI}=1.29-5.57, \mathrm{p}=0.008$ ) were associated with nonadherence coping strategy to relieve the adverse effects of ART. Conclusion. The present study revealed that positive emotion coping was the most commonly used strategy. Age, level of education, and distance from health institution were the predictors of nonadherence coping strategy.

\section{Introduction}

Adverse drug reactions (ADRs) are any noxious, unintended, and undesired effect of a drug, which occurs at doses used in humans for prophylaxis, diagnosis, or therapy, or for the modification of physiological functions $[1,2]$, while symptoms are subjective complaint that is reported by patients due to some disease state or medications. Adverse effects from ART are common and were the most common reason for switching or discontinuing therapy and for medication nonadherence $[3,4]$. Adverse effects are not typically life-threatening but can impact the quality of life (QoL), 
negatively affect patients' willingness to adhere to their regimens, and influence decisions about healthcare $[5,6]$. A better understanding of how patients cope with undesirable adverse effects from treatment can inform interventions to remediate the negative impact of adverse effects on treatment adherence and QoL. Coping is defined as the cognitive and behavioral responses that an individual employs to deal with the stressors. Coping can take the form of active behavior (problem-focused), regulation of distress (emotion-focused), or the maintenance of well-being (meaning-based) [7]. One of the major challenges for patient being nonadherent to their ART is the incidence of ADRs. The main coping strategies for adverse effect of ART include nonadherence, social support seeking, using positive emotion, information seeking, and taking other medications $[4,7-12]$.

There was evidence that ADRs prevalence and incidence in ART programs are much higher and have a wide range of manifestations. Various studies demonstrate that adverse effect of ART regimens was the main reason for nonadherence $[13,14]$. Nonadherence to ART regimens is common, leading to considerable deterioration of the disease and enhanced healthcare expenditure. Though nonadherence coping strategy in ART is an increasing problem for patients with HIV, it has not been extensively studied in patients with HIV. Previous studies have reported that 59.38\% [15], $14.5 \%$ [3], and $17.3 \%$ [16] of HIV patients were nonadherent in United States, Nepal, and Ethiopia, respectively, and avoidance of adverse effect was the main reason contributing to nonadherence. Previous study in South Africa demonstrated that the primary reason for ART regimen changes was adverse effect related to drugs [17]. The prevalence and incidence of ADR in ART is rising globally [18]. Its incidence in different studies was found in $43.8 \%$ [19] and 6.3\% [18] of HIV patients with ART in India and Nigeria, respectively. Studies in India reported ADR prevalence of $39.7 \%$ in intensively monitored ART patients [20]. In Ethiopia among ADR reports from 2002 to 2007, ADRs from ART contribute about $70.6 \%$ [6] and in other studies in Harar, Northern Ethiopia, and Gondar the prevalence of ADR with ART was 17\%, 19\%, and $89.8 \%$, respectively $[13,21,22]$. Nonadherence will lead to higher viral load, drug resistance, and treatment failure. Evidence-based research that evaluates how often patients use different coping strategies to counteract the adverse effects of ART in developing countries such as Ethiopia is scanty [22]. Thus, there should be a continuing need to routinely assess coping strategies and their contributing factors for patients with HIV in health facilities [8, 23]. This is particularly imperative in resource-limited countries, with the predominance of economic instability and inadequate follow-up that might contribute to the incidence of poor medication adherence. Therefore, this study aimed to assess coping strategies for adverse effects of ART among adult HIV patients attending the UoGRH.

\section{Methods}

2.1. Study Design and Setting. A cross-sectional study design was conducted from February to March 2017 at UoGRH
HIV clinic, Northwest Ethiopia. The hospital gives different inpatient and outpatient services for the community (around seven million catchment population). This hospital renders comprehensive HIV related services including voluntary counseling and testing (VCT), provider initiated testing and counseling (PITC), prevention of mother to child transmission (PMTCT), and ART program. Currently, there are about 5194 HIV patients actively attending ART in the hospital, having the daily patient flow of 150 on average.

2.2. Study Subjects. Adults with age $\geq 18$ years who were on ART for at least one month and those who came for refill during the period of data collection and who had ART associated adverse effects were included in the study. ART associated adverse effects, which are a harmful or abnormal result caused by administration of medication (ART), were the most common reason for switching or discontinuing therapy and for medication nonadherence.

2.3. Sample Size and Sampling Methods. Sample size was computed by using single population proportion formula as follows:

$$
\mathrm{n}=\frac{\mathrm{Z}_{(\alpha / 2)^{2}} \mathrm{p}(1-\mathrm{p})}{\mathrm{d}^{2}}
$$

where $n$ is expected sample size for population $>10,000$; $\alpha / 2$ is the critical value of a $95 \%$ confidence level interval (which corresponds to 1.96); and $P$ means that we use positive prevalence estimated, to maximize sample size. Negative prevalence $=1-0.5=0.5, d=$ marginal error $(d=0.05)$; then the sample size is

$$
\mathrm{n}=\frac{1.96^{2} 0.5(1-0.5)}{(0.05)^{2}}=384.16=\sim 384
$$

Since the source of population was less than 10,000 $(\mathrm{N}=5194)$, reduction formula was employed to compute the final sample size. The corrected sample size, using the following correction formula, was 357.6 358,

$$
\text { Corrected sample size }=\frac{n \times N}{n+N}
$$

Accordingly, the final sample size with $10 \%$ contingency was found to be 394 .

A systematic random sampling method was employed to recruit the study participants in each day of the data collection process.

2.4. Data Collection Techniques. Adequate training was given for three pharmacists, who were recruited as data collectors. The training comprised uniform interpretation of the structured questionnaires, strict use of study criterion, explanation of the study objectives, getting oral consents, implementation of sampling technique, and maintaining confidentiality of the collected data. Data were collected by interviewing HIV patients who visited the HIV clinic during the study period using a validated structured questionnaire composed of 
TABLE 1: Sociodemographic characteristics of the study participants.

\begin{tabular}{|c|c|c|}
\hline Characteristics & Category & Frequency $(\%)$ \\
\hline \multirow[t]{5}{*}{ Age } & $18-24$ years & $11(2.8)$ \\
\hline & $25-34$ years & $130(33)$ \\
\hline & $35-44$ years & $150(38.1)$ \\
\hline & 45- 54 years & $78(19.8)$ \\
\hline & $>54$ years & $25(6.3)$ \\
\hline \multirow[t]{5}{*}{ Educational status } & Can't read \& write & $84(21.3)$ \\
\hline & Can read \& write & $53(13.4)$ \\
\hline & Grade $1-8^{\text {th }}$ & $100(25.4)$ \\
\hline & Grade $9-12^{\text {th }}$ & $81(20.6)$ \\
\hline & College/university & $76(19.3)$ \\
\hline \multirow[t]{7}{*}{ Occupation } & Government employee & $87(22.1)$ \\
\hline & Merchant & $99(25.1))$ \\
\hline & Farmer & $30(7.6)$ \\
\hline & Student & $7(1.8)$ \\
\hline & Daily laborer & $65(16.5)$ \\
\hline & Housewife & $84(21.3)$ \\
\hline & Others* & $22(5.6)$ \\
\hline \multirow[t]{4}{*}{ Marital status } & Single & $66(16.8)$ \\
\hline & Married & $204(51.8)$ \\
\hline & Divorced & $65(16.5)$ \\
\hline & Widowed & $59(15)$ \\
\hline \multirow[t]{4}{*}{ Ethnicity } & Amhara & $309(78.4)$ \\
\hline & Kimant & $58(14.7)$ \\
\hline & Tigrie & $24(6.1)$ \\
\hline & Awi & $3(0.8)$ \\
\hline
\end{tabular}

${ }^{*}$ Retired and those who had no work.

closed and open ended questions. The structured questionnaire was assessed by an expert in the field of ART for clarity and comprehensiveness of its contents. The questionnaire was first prepared in English and translated to local language (Amharic) for ease of understanding. A pilot study was done with $5 \%$ (20) of the study participants and all the necessary modifications were done before implementing in the main study.

2.5. Data Analysis. Data were entered into Epi-Info and analyzed by using SPSS version 20.0 statistical software. Patients' baseline sociodemographic data and the frequency of major adverse effects were summarized using descriptive statistics. Univariable and multivariable binary logistic regression were conducted to determine the potential predictors of nonadherence coping strategy. Confidence interval (95\%) and p value were used or reported in each logistic regression analysis. $\mathrm{p}$ value $\leq 0.05$ was considered as statistically significant.

2.6. Ethical Consideration. Ethical clearance was obtained from Ethical Approval Committee, University of Gondar, College of Medicine and Health Sciences. Letter of permission was submitted to University of Gondar Referral Hospital medical director office prior to the beginning of the study. Verbal informed consent was obtained from participants before conducting the study. Participants were informed that their participation was voluntary and they can withdraw from the study at any stage if they desire without any penalty. Confidentiality of participants was maintained at all levels of the study and the name and address of the patient were omitted from the questionnaire.

\section{Results}

3.1. Sociodemographic Characteristics of HIV Patients. Three hundred and ninety-four HIV patients were involved in the study. About two-thirds of study participants were females and majorities (38.1\%) of the study participants were within the age group of 35-44 years. Mean age of the study participants was $38.3(\mathrm{SD}=9.8)$ years. Being married (51.8\%) and orthodox (78.7\%) participants accounted for the highest percentage. Being merchant (25.1\%) and government employee $(22.1 \%)$ accounted for the highest percentage of occupation. Education-wise, $25.4 \%$ attended primary and higher education (Table 1).

3.2. Clinical Characteristics and Health Conditions. The median CD4 count before ART initiation among the study participants, who faced ART adverse effect, was 153.5 with IQR of 624, while the most recent CD4 count was 384.5 with 
TABLE 2: Clinical characteristics and health conditions among patients with HIV/AIDS.

\begin{tabular}{|c|c|c|}
\hline Characteristics & Category & Frequency (\%) \\
\hline \multirow[t]{4}{*}{ WHO clinical stage } & Stage I & $93(23.6)$ \\
\hline & Stage II & $75(19)$ \\
\hline & Stage III & $173(43.9)$ \\
\hline & Stage IV & $53(13.5)$ \\
\hline \multirow[t]{3}{*}{ Treatment $(\mathrm{T})$ stage } & $\mathrm{T} 1$ & $377(95.7)$ \\
\hline & $\mathrm{T} 2$ & $12(3)$ \\
\hline & $\mathrm{T} 3$ & $5(1.3)$ \\
\hline \multirow[t]{3}{*}{ Baseline functional status } & Working & $307(77.9)$ \\
\hline & Ambulatory & $61(15.5)$ \\
\hline & Bedridden & $26(6.6)$ \\
\hline \multirow[t]{3}{*}{ Current functional status } & Working & $389(98.7)$ \\
\hline & Ambulatory & $5(1.3)$ \\
\hline & Bedridden & $0(0)$ \\
\hline
\end{tabular}

TABLE 3: Documented reasons for changing ART regimens at University of Gondar.

\begin{tabular}{lccc}
\hline Reasons of ART changes & $\mathbf{1}^{\text {st }}$ change (\%) & $\mathbf{2}^{\text {nd }}$ change (\%) & $3^{\text {rd }}$ change (\%) \\
\hline (1) Adverse effect & $73(61.9)$ & $10(45.5)$ & $3(30)$ \\
$(2)$ TB & $11(9.3)$ & $0(0)$ & $0(0)$ \\
(3) Pregnancy & $1(0.8)$ & $1(4.5)$ & $0(0)$ \\
(4) Rx. failure & $16(13.6)$ & $5(22.7)$ & $0(0)$ \\
(5) Unknown & $17(14.4)$ & $1(4.5)$ & $1(10)$ \\
(6) Unavailability & $0(0)$ & $5(22.7)$ & $6(60)$ \\
\hline $\mathbf{N}$ & $\mathbf{1 1 8}$ & $\mathbf{2 2}$ & $\mathbf{1 0}$ \\
\hline
\end{tabular}

IQR of 408.8. The majority (43.9\%) of the study participants were World Health Organization (WHO) clinical stage III at the time of starting ART, while at the time of data collection majority $(95.7 \%)$ of study participants were treatment stage 1 (T1). Baseline functional status of the study participants was majorly working (77.9\%) while a significant number of patients had ambulatory and bedridden functional status. Nonetheless, the current functional status for almost all (98.7\%) of HIV patients was working (Table 2).

3.3. Reasons for Changing ART Regimen. Based on documented reasons from the patient's chart, 118 (29.9\%) patients who started ART regimens were changed due to different reasons. Adverse effects (61.9\%) were the most common reason for regimen change. Of 118 changed regimens, majority (64, $54.2 \%)$ of them were on D4T based ART regimen followed by $\operatorname{AZT}(34,28.8 \%)$ based regimen and TDF $(20,17 \%)$ (Table 3).

3.4. Adverse Effects Experienced by HIV Patients. A total of 880 adverse effects were reported which was on average greater than two adverse effects experienced per patient and the majority of adverse effects were central nervous systems (CNS) and peripheral nervous systems (PNS) (62\%), metabolic disorders (16.4\%), gastrointestinal (GI) (8.6\%), skin (9\%), and others (4\%). Headache (190, 48.2\%), fatigue $(71,18 \%)$, loss of appetite $(69,17.5 \%)$, burning sensation $(52$,
$13.2 \%)$, back pain $(50,12.7 \%)$, and itching $(44,11.2 \%)$ were the most noticeable adverse effects experienced by the study participants (Table 4).

Of 394 study participants who had adverse effect, majority $(150,38.1 \%)$ were on TDF/3TC/EFV ART regimen followed by AZT/3TC/NVP (124, 31.5\%) (Table 5).

3.5. Coping Strategies. The present study showed that positive emotions, social support seeking, taking other medicines to treat ART adverse effect, information seeking, nonadherence, and holy water were used by $91.1 \%, 76.6 \%, 76.6 \%, 48.7 \%$, $35.5 \%$, and $45.9 \%$ of study participants, respectively, as coping strategies for adverse effects of ART (Table 6).

3.6. Factors Associated with Coping Strategies Taken by HIV Patients. After controlling different demographic, economical, and other factors through the use of multivariate logistic regression analysis, this study showed that only age, educational status, occupation, and distance were found significantly associated with nonadherence coping strategy for adverse effect of ART ( $\mathrm{p} \leq 0.05)$. HIV patients in the age groups of 18-24 years and 25-34 years were more likely to use nonadherence as coping strategy for adverse effect compared to patients' age above 54 years $(\mathrm{AOR}=29.54,95 \%$ $\mathrm{CI}=2.49-350.25$ and $\mathrm{AOR}=3.90,95 \% \mathrm{CI}=1.24-12.28)$, respectively.

HIV patients who could not read and write and who had primary school education were more likely to use 
TABLE 4: Frequency distribution of adverse effects experienced by HIV patients who wereattending HIV clinic at UoGRH.

\begin{tabular}{|c|c|c|c|}
\hline \multicolumn{2}{|c|}{$\begin{array}{l}\text { Type of Adverse effects } \\
\end{array}$} & $\begin{array}{c}\text { Number of HIV patients } \\
\text { N (\%) }\end{array}$ & $\begin{array}{c}\text { Number of adverse effects } \\
\qquad \mathbf{N}(\%)\end{array}$ \\
\hline Central Nervous & Headache & $190(48.2)$ & $190(21.6)$ \\
\hline System (CNS) \& & Sedation & $12(3)$ & $12(1.4)$ \\
\hline Peripheral nervous & Hallucination & $25(6.3)$ & $25(2.8)$ \\
\hline \multirow[t]{9}{*}{ system (PNS) } & Anxiety & $42(10.7)$ & $42(4.8)$ \\
\hline & Nervousness & $26(6.6)$ & $26(3)$ \\
\hline & Insomnia & $42(10.7)$ & $42(4.8)$ \\
\hline & Forgetfulness & $26(6.6)$ & $26(3)$ \\
\hline & Vertigo & $36(9.1)$ & $36(4.1)$ \\
\hline & Tinnitus & $14(3.6)$ & $14(1.6)$ \\
\hline & Back pain & $50(12.7)$ & $50(5.7)$ \\
\hline & Peripheral numbness & $30(7.6)$ & $30(3.4)$ \\
\hline & Burning sensation & $52(13.2)$ & $52(5.9)$ \\
\hline \multicolumn{3}{|c|}{ Total CNS \& peripheral adverse effects } & $545(62)$ \\
\hline \multirow[t]{4}{*}{ Gastrointestinal (GI) } & Gastritis & $38(9.6)$ & $38(4.3)$ \\
\hline & Vomiting & $12(3)$ & $12(1.4)$ \\
\hline & Diarrhea & $10(2.5)$ & $10(1.1)$ \\
\hline & Nausea & $16(4.1)$ & $16(1.8)$ \\
\hline Total GI adverse effe & & & $76(8.6)$ \\
\hline \multirow[t]{3}{*}{ Skin } & Skin rash & $21(5.3)$ & $21(2.4)$ \\
\hline & Itching & $44(11.2)$ & $44(5)$ \\
\hline & Sweating & $14(3.6)$ & $14(1.6)$ \\
\hline Total skin adverse ef & & & $79(9)$ \\
\hline \multirow[t]{4}{*}{ Metabolic } & Loss of appetite & $69(17.5)$ & $69(7.8)$ \\
\hline & Fatigue & $71(18)$ & $71(8.1)$ \\
\hline & Lipodystrophy & $3(0.8)$ & $3(0.3)$ \\
\hline & Hyperglycemia & $2(0.5)$ & $2(0.2)$ \\
\hline \multicolumn{2}{|c|}{ Total Metabolic adverse effects } & & $145(16.4)$ \\
\hline \multirow[t]{5}{*}{ Others } & Anemia & $8(2)$ & $8(0.9)$ \\
\hline & Vision problem & $13(3.3)$ & $13(1.5)$ \\
\hline & Loss of sexual desire & $3(0.8)$ & $3(0.3)$ \\
\hline & Bloating & $5(1.3)$ & $5(0.6)$ \\
\hline & Crampy abdominal pain & $6(1.5)$ & $6(0.7)$ \\
\hline \multicolumn{3}{|c|}{ Total other adverse effects } & $35(4)$ \\
\hline \multicolumn{3}{|c|}{ Grand total adverse effects } & $880(100)$ \\
\hline
\end{tabular}

nonadherence as coping strategy for adverse effect compared to patients who had higher level of education $(\mathrm{AOR}=5.70$, $95 \% \mathrm{CI}=2.16-15.05$ and $\mathrm{AOR}=2.98,95 \% \mathrm{CI}=1.19-7.48)$, respectively.

Respondents who were merchants, farmers, and daily labors and who had no work used nonadherence more likely compared to those who were government employees (AOR $=10.48,95 \% \mathrm{CI}=3.82-28.78 ; \mathrm{AOR}=21.24,95 \% \mathrm{CI}=$ 3.74-78.54; $\mathrm{AOR}=10.49,95 \% \mathrm{CI}=3.30-33.35$; and $\mathrm{AOR}=$ $4.88,95 \%$ CI $=1.18-20.19)$, respectively. Respondents who were living far $(>20 \mathrm{~km})$ from the hospital used nonadherence coping strategy more likely compared to those who were nearby $(\leq 20 \mathrm{~km})(\mathrm{AOR}=2.68,95 \% \mathrm{CI}=1.29-5.57)$ (Table 7).

\section{Discussion}

The present study was aimed at assessing the major adverse effects of ART and coping strategies taken by HIV patients for these adverse effects. About 394 HIV patients who had adverse effects were studied for coping strategy(s) of the adverse effect they faced. They used five coping strategies (positive emotion, social support seeking, information seeking, taking other medications, and nonadherence).

This study revealed that adverse effects were the most common reason for ART regimen changes in HIV patients. Nearly one-third of HIV patients ART regimens were changed due to different reasons based on patient's chart review. Out of 118 regimen changes $73(61.9 \%)$ were due to 


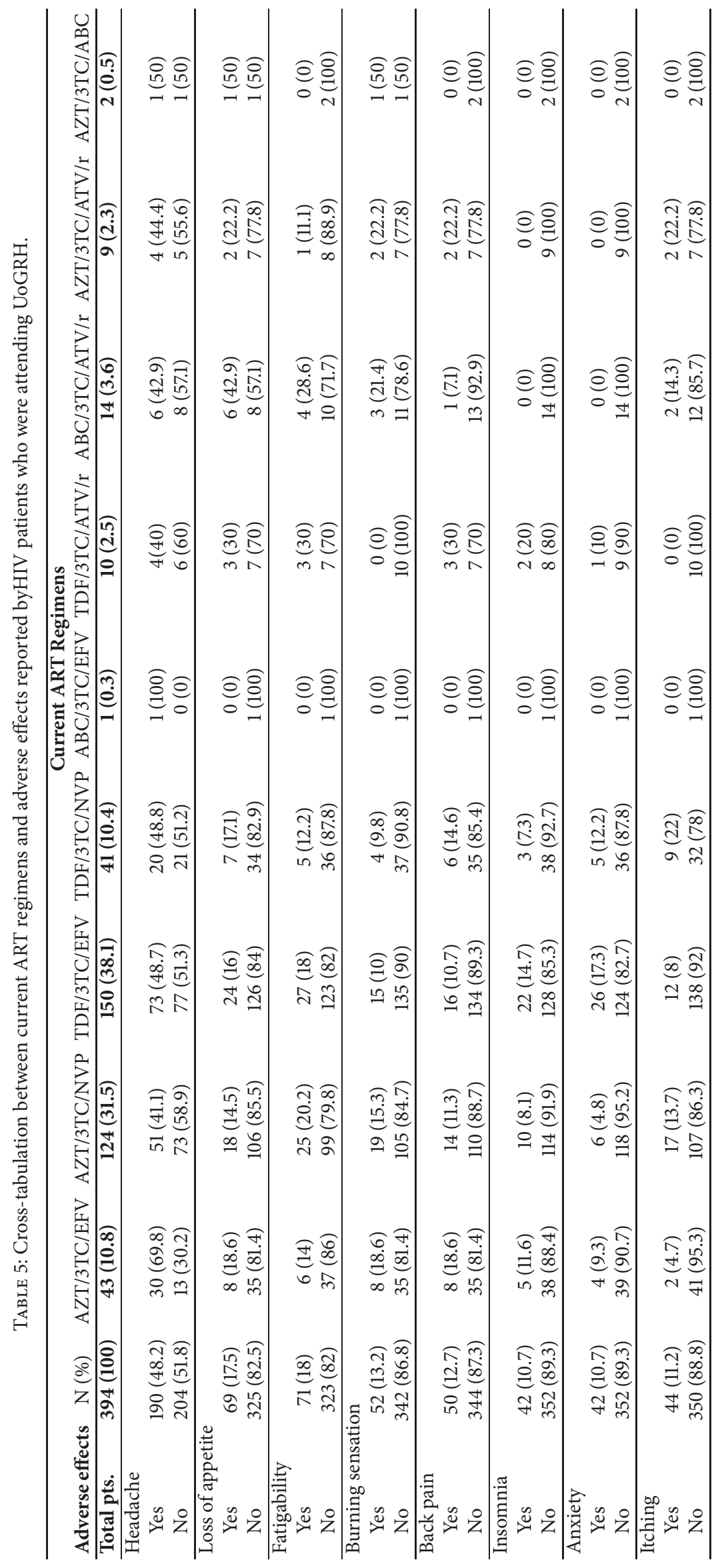


TABLE 6: Responses for each coping strategy for adverse effects of ART by HIV patientswho were attending HIV clinic at UoGRH.

\begin{tabular}{lcc}
\hline Coping strategy & Responses & No (\%) \\
\hline & Yes $(\%)$ & $35(8.9)$ \\
Positive emotion & $359(91.1)$ & $92(23.4)$ \\
Seeking social support & $302(76.6)$ & $254(64.5)$ \\
Non-adherence & $140(35.5)$ & $202(51.3)$ \\
Information seeking & $192(48.7)$ & $92(23.4)$ \\
Take other medicines & $302(76.6)$ & $213(54.1)$ \\
Holy water** & $181(45.9)$ & \\
\hline
\end{tabular}

${ }^{* *}$ Used with the five main coping strategies.

TABLE 7: Univariate and multivariate analysis of factors associated with nonadherence coping strategy at UoGRH.

\begin{tabular}{|c|c|c|c|c|c|c|}
\hline \multirow{2}{*}{ Variables } & \multicolumn{3}{|c|}{ Non-adherence coping } & \multirow{2}{*}{ COR $(95 \% \mathrm{CI})$} & \multirow{2}{*}{$\operatorname{AOR}(95 \% \mathrm{CI})$} & \multirow{2}{*}{$P$ - value } \\
\hline & Yes $(\%)$ & No (\%) & Total (n) & & & \\
\hline \multicolumn{7}{|l|}{ Age (years) } \\
\hline $18-24$ & $10(90.9)$ & $1(9.1)$ & 11 & $31.66(3.33-300.81)$ & $29.54(2.49-350.25)$ & $0.007^{*}$ \\
\hline $25-34$ & $71(54.6)$ & $59(45.4)$ & 130 & $3.81(1.43-10.16)$ & $3.90(1.24-12.28)$ & $0.020^{*}$ \\
\hline $35-44$ & $42(28)$ & $108(72)$ & 150 & $1.23(0.46-3.30)$ & $1.51(0.48-4.79)$ & 0.485 \\
\hline $45-54$ & $11(14.1)$ & $67(85.9)$ & 78 & $0.52(0.17-1.59)$ & $0.44(0.12-1.62)$ & 0.219 \\
\hline$>54$ & $6(24)$ & $19(76)$ & 25 & 1 & 1 & \\
\hline \multicolumn{7}{|l|}{ Occupation } \\
\hline Government employee & $8(9.2)$ & $79(90.8)$ & 87 & 1 & 1 & \\
\hline Merchant & $56(56.6)$ & $43(43.4)$ & 99 & $12.86(5.61-29.45)$ & $10.48(3.82-28.78)$ & $0.001^{*}$ \\
\hline Farmer & $18(60)$ & $12(40)$ & 30 & $14.81(5.28-41.52)$ & $21.24(5.74-78.54)$ & $0.001^{*}$ \\
\hline Student & $2(28.6)$ & $5(71.4)$ & 7 & $3.95(0.65-23.75)$ & $7.18(0.93-55.65)$ & 0.059 \\
\hline Daily labourer & $32(49.2)$ & $33(50.8)$ & 65 & $9.57(3.99-22.96)$ & $10.49(3.30-33.35)$ & $0.001^{*}$ \\
\hline Housewife & $17(20.2)$ & $67(79.8)$ & 84 & $2.51(1.02-6.17)$ & $2.69(0.89-8.10)$ & 0.079 \\
\hline Retired \& had no work & $7(31.8)$ & $15(68.2)$ & 22 & $4.61(1.45-14.63)$ & $4.88(1.18-20.19)$ & $0.029^{*}$ \\
\hline \multicolumn{7}{|l|}{ Educational status } \\
\hline Can't read \& write & $45(53.6)$ & $39(46.4)$ & 84 & $5.11(2.48-10.51)$ & $5.70(2.16-15.05)$ & $0.001^{*}$ \\
\hline Can read \& write & $26(49.1)$ & $27(50.9)$ & 53 & $4.26(1.93-9.41)$ & $2.02(0.73-5.59)$ & 0.175 \\
\hline Primary $\left(1-8^{\text {th }}\right)$ & $46(46)$ & $54(54)$ & 100 & $3.77(1.87-7.60)$ & $2.98(1.19-7.48)$ & $0.020^{*}$ \\
\hline Secondary $\left(9-12^{\text {th }}\right)$ & $9(11.1)$ & $72(88.9)$ & 81 & $0.55(0.22-1.37)$ & $0.38(0.13-1.13)$ & 0.083 \\
\hline Above $12^{\text {th }}$ & $14(18.4)$ & $62(81.6)$ & 76 & 1 & 1 & \\
\hline \multicolumn{7}{|l|}{ Distance $(\mathbf{k m})$} \\
\hline $1-20$ & $108(33.2)$ & $217(66.8)$ & 325 & 1 & 1 & \\
\hline$>20$ & $32(46.4)$ & $37(53.6)$ & 69 & $1.74(1.03-2.94)$ & $2.68(1.29-5.57)$ & $0.008^{*}$ \\
\hline
\end{tabular}

$\mathrm{COR}=$ crude odds ratio, $\mathrm{AOR}=$ adjusted odds ratio, and $\mathrm{CI}=$ confidence interval.

adverse effects followed by unknown reasons (17) (14.4\%), due to treatment failure (16) (13.6\%), development of tuberculosis (TB) (11) (9.3\%), and pregnancy (1) (0.8\%). This regimen change due to adverse effect is higher compared to a study carried out in Jimma University Specialized Hospital (30\%). Similarly, treatment failure contributed more to ART regimen change in this study than the above study $(0.38 \%)$. However, tuberculosis drug interactions and pregnancy were lesser reasons for ART regimen change in this study than Jimma study (17.1\%, 3.3\%), respectively [24]. The probable reason might be due to variations in ART regimens. Regarding the type of ART regimen, about $91.6 \%$ of ART regimens were first line, which is less compared to another study in Debre Markos (98\%) [25]. The probable reason for this variation might be because patients may get different strength of counseling regarding the importance of medication adherence.

The present study revealed that a total of 880 ART adverse effects were reported in 394 HIV patients. On average each patient had a chance of facing three adverse effects from their ART regimen which is in contrast with a study done in Uganda, which reported an average of five side effects [26]. This could probably be due to differences in patient's report of adverse effects. The most common adverse effects based on organ system classification reported by the study participants in this study were CNS and PNS (62\%), metabolic disorder (16.4\%), gastrointestinal (8.6\%), skin (9\%), and others (4\%). A similar study by Lorio et al. also reported that central 
nervous system (45\%), gastrointestinal (27\%), and dermatologic $(18 \%)$ were the major adverse effects in HIV patients [27]. This might be due to ART regimen. In this study the most common adverse effects reported by the participants were headache $(48.2 \%)$, fatigability $(18 \%)$, loss of appetite (17.5\%), burning sensation (13.2\%), back pain (12.7\%), itching $(11.2 \%)$, and insomnia (10.7\%). Some of these adverse effects are similar to other studies done in different countries [26, $28]$. In this study fatigability (18\%) was almost comparable to a study in San Francisco (17\%), but much lower than studies in Uganda $(67.5 \%)$ and France $(73.4 \%)$ [7, 26, 28]. Loss of appetite $(17.5 \%)$ was among the major adverse effects reported by study participants in this study which is almost similar to France study (16.9\%), but lower than Ugandan study (53\%) $[26,28]$. Most HIV patients in this study reported headache (48.2\%). This finding is in agreement with other studies by Agu et al. reported that headache (14.6\%) in 2012, (9.4\%)) in 2013 and France $(34.6 \%)$ [18, 28, 29]. In this study gastritis (9.6\%) was reported by HIV patients. Similarly, a study in India reported that gastritis (13.13\%) was among the major adverse effects [30]. A study in Ethiopia, HFSH, reported that the major adverse effect was lipodystrophy (49.2\%) (18), but in this study only $3(0.8 \%)$ study participants were reported. The probable reason for the variations might be the type of ART regimen that patients were taking. In HFSH study, majority $(80.3 \%)$ of patients were taking a regimen that contains Stavudine (D4T) as a first line, but in this study currently none of HIV patients were taking ART regimen containing D4T because of adverse effect (toxicity) [21].

Five main coping strategies for adverse effects of ART were used by HIV patients (positive emotion, social support seeking, nonadherence, information seeking, and taking other medications). The majority (91.1\%) of participants in this study used positive emotion coping followed by social support seeking $(76.6 \%)$, taking other medicines $(76.6 \%)$, information seeking (48.7\%), and nonadherence (35.5\%). Contrastingly, a study conducted in San Francisco revealed that nonadherence was the most used coping strategy for adverse effect of ART [7]. The reason for the variations might be due to the current functional status of study participants. In this study, almost all (98.7\%) study participants were working and only $1.3 \%$ had ambulatory functional status compared to a study in San Francisco, where $71 \%$ of study participants were not functionally working.

Although majority (91.1\%) of the study participants were using positive emotion, there were also a significant number of patients (35.5\%) who used nonadherence as a coping strategy in this study. Similarly, in other studies, $17 \%$ (France) [28], 14.4\% (Nigeria) [18], and 27\% (Uganda) [26] of HIV patients used nonadherence as coping strategy for adverse effect of ART.

In this study information seeking (48.7\%) was less likely used by HIV patients compared to Uganda study (91.2\%). This variation might be due to educational status variations. In this study (21.3\%) HIV patients could not read and write compared to only $4.8 \%$ who never had formal education.

In the present study participant's age was significantly associated with nonadherence as a coping strategy. Study participants aged between 18 and 24 years and 25 and 34 years were more likely to use nonadherence as coping strategy for adverse effect than those who were above 54 years which is similar to a study in Nigeria [29]. It is inconsistent with another study finding in Uganda, which reported that nonadherence to ART was not statistically significant with any demographic factors [26]. The probable reasons might be due to the fact that young people did not worry about the consequences of being nonadherent to their ART regimen.

Study participants who were merchants, farmers, and daily laborers and those who had no work used nonadherence as a coping strategy more likely than those who were government employees [29]. This is inconsistent with study in Arsi zone, Oromia, where employment was associated with nonadherence [23]. The possible reasons might be indirectly related to educational status, being busy at work, and being worried about having no work. This finding is also supported by different studies $[23,31]$. Study participants who could not read and write and who were learning in primary schools were more likely to use nonadherence as coping strategy for adverse effect than those who were above $12^{\text {th }}$ grade. This is in agreement with study in Kenya, which stated that educational status was associated with nonadherence as a coping strategy [31].

Distance from study participant's home to the health institution (UoGRH) was also significantly associated with nonadherence coping strategy. Those who accessed the health institution far away ( $>20 \mathrm{~km}$ ) from their home were found to more likely use nonadherence as a coping strategy than those who were nearby $(\leq 20 \mathrm{~km})$. This is in line with a study done in Nigeria, which found that those who accessed the health institution far away from their home were found to be nonadherent [32]. This is inconsistent with study done in Arsi zone [23]. These variations might be because distance was categorized as those who were in the town Gondar (20 $\mathrm{km}$ ) and outside Gondar town $(>20 \mathrm{~km})$ transport problem and cost for transport, but in Arsi those in walking (5 km) and beyond $5 \mathrm{~km}$.

4.1. Limitations of the Study. The present study does have some limitations. Due to financial constraints coping strategies were assessed through a self-reporting questionnaire only, which may overestimate the response. The second major limitation of this study is that the respondents consisted only of patients who actually went to ART clinics. We did not interview people who were picking up ART drugs for someone else and this means that we may have missed patients too sick to attend appointments. The final major limitation of this study was the wider confidence interval in the first age category. This resulted from relatively smaller sample size in this age group.

\section{Conclusion}

The present study revealed that positive emotion coping was the most commonly used strategy. Age, level of education, and distance from health institution were the predictors of nonadherence coping strategy. 


\section{Abbreviations and Acronyms}

$\begin{array}{ll}\text { 3TC: } & \text { Lamivudine } \\ \text { ABC: } & \text { Abacavir } \\ \text { ADR: } & \text { Adverse drug reaction } \\ \text { AIDS: } & \text { Acquired Immune Deficiency Syndrome } \\ \text { AOR: } & \text { Adjusted odds ratios } \\ \text { ART: } & \text { Antiretroviral therapy } \\ \text { ATV/r: } & \text { Atazanavir/ritonavir } \\ \text { AZT: } & \text { Zidovudine } \\ \text { CD4: } & \text { Cluster of Differentiation } 4 \\ \text { CI: } & \text { Confidence interval } \\ \text { EFV: } & \text { Efavirenz } \\ \text { HIV: } & \text { Human immunodeficiency virus } \\ \text { IQR: } & \text { Interquartile range } \\ \text { NVP: } & \text { Nevirapine } \\ \text { QoL: } & \text { Quality of life } \\ \text { SD: } & \text { Standard deviation } \\ \text { SPSS: } & \text { Statistical Package for Social Sciences } \\ \text { TDF: } & \text { Tenofovir Disoproxil Fumarate } \\ \text { UoGRH: } & \text { University of Gondar Referral Hospital } \\ \text { WHO: } & \text { World Health Organization. }\end{array}$

\section{Data Availability}

The data used to support the findings of this study are available from the corresponding author upon request.

\section{Ethical Approval}

Approval and permission were sought from Ethical Review Board of College of Medicine and Health Sciences, University of Gondar.

\section{Conflicts of Interest}

We declare that there are no conflicts of interest to disclose.

\section{Authors' Contributions}

Yitayih Kefale Gelaw conducted the actual study and the statistical analysis. Yitayih Kefale Gelaw, Boressa Adugna, Adino Tesfahun Tsegaye, Tadesse Melaku, and Belayneh Kefale were involved in developing the idea, designing the study, and writing the manuscript. All authors approved the submitted version of the manuscript.

\section{Acknowledgments}

We would like to acknowledge University of Gondar for financial support towards this project.

\section{References}

[1] S. Olsson, "The role of the WHO programme on international drug monitoring in coordinating worldwide drug safety efforts," Drug Safety, vol. 19, no. 1, pp. 1-10, 1998.

[2] K. Khan, A. H. Khan, S. A. Sulaiman, C. Ting Soo, and A. Akhtar, "Adverse drug reactions in HIV/AIDs patients at a tertiary care hospital in Penang, Malaysia," Japanese Journal of Infectious Diseases, vol. 69, no. 1, pp. 56-59, 2016.

[3] S. P. Wasti, P. Simkhada, J. Randall, J. V. Freeman, E. van Teijlingen, and W. Cameron, "Factors Influencing Adherence to Antiretroviral Treatment in Nepal: A Mixed-Methods Study," PLoS ONE, vol. 7, no. 5, p. e35547, 2012.

[4] D. Olem, K. M. Sharp, J. M. Taylor, and M. O. Johnson, "Overcoming barriers to HIV treatment adherence: A brief cognitive behavioral intervention for HIV-positive adults on antiretroviral treatment," Cognitive and Behavioral Practice, vol. 21, no. 2, pp. 206-223, 2014.

[5] D. Joseph, Pharmacotherapy: A pathophysiologic approach, McGraw-Hill Medical, 2008.

[6] A. Ermias, G. Gurmesa, M. Mesfin, and A. Mengistu, "Adverse drug reaction monitoring in Ethiopia: Analysis of case reports, 2002-2007," Ethiopian Journal of Health Development, vol. 25, no. 2, pp. 168-173, 2011.

[7] M. O. Johnson and T. B. Neilands, "Coping with HIV treatment side effects: Conceptualization, measurement, and linkages," AIDS and Behavior, vol. 11, no. 4, pp. 575-585, 2007.

[8] E. Sabaté, Adherence to long-term therapies: evidence for action, World Health Organization, 2003.

[9] R. Mccraty and D. Tomasino, "Emotional Stress, Positive Emotions, and Psychophysiological Coherence," Stress in Health and Disease, pp. 342-365, 2006.

[10] T. D. Wilson, "Human Information Behavior," Informing Science: The International Journal of an Emerging Transdiscipline, vol. 3, pp. 049-056, 2000.

[11] G. Barker, A. Olukoya, and P. Aggleton, "Young people, social support and help-seeking," International Journal of Adolescent Medicine and Health, vol. 17, no. 4, 2005.

[12] A. Parcesepe, O. Tymejczyk, R. Remien et al., "HIV-Related Stigma, Social Support, and Psychological Distress Among Individuals Initiating ART in Ethiopia," AIDS and Behavior, pp. 1-11, 2018.

[13] B. B. Gebrezgabher, Y. Kebede, M. Kindie, D. Tetemke, M. Abay, and Y. A. Gelaw, "Determinants to antiretroviral treatment non-adherence among adult HIV/AIDS patients in northern Ethiopia," AIDS Research and Therapy, vol. 14, no. 1, 2017.

[14] B. Tsega, B. A. Srikanth, and Z. Shewamene, "Determinants of non-adherence to antiretroviral therapy in adult hospitalized patients, Northwest Ethiopia," Patient Preference and Adherence, vol. 9, pp. 373-380, 2015

[15] M. Vyavaharkar, L. Moneyham, A. Tavakoli et al., "Social support, coping, and medication adherence among HIV-positive women with depression living in rural areas of the southeastern United States," AIDS Patient Care and STDs, vol. 21, no. 9, pp. 667-680, 2007.

[16] B. Tessema, F. Biadglegne, A. Mulu, A. Getachew, F. Emmrich, and U. Sack, "Magnitude and determinants of nonadherence and nonreadiness to highly active antiretroviral therapy among people living with HIV/AIDS in Northwest Ethiopia: A cross sectional study," AIDS Research and Therapy, vol. 7, 2010.

[17] N. M. Dube, R. Summers, K.-S. Tint, and G. Mayayise, "A pharmacovigilance study of adults on highly active antiretroviral therapy, South Africa: 2007 - 2011," Pan African Medical Journal, vol. 11, p. 39, 2012.

[18] K. A. Agu, M. A. Isah, D. Oqua, M. A. Habeeb, P. O. Agada, and S. I. Ohiaeri, "Incidence of adverse drug reactions in Patients on Antiretroviral Therapy: A study of Pharmaceutical Care in HIV Interventions in Nigeria," West African Journal of Pharmacy, vol. 19, no. 24, 2013. 
[19] R. Rajesh, S. Vidyasagar, and K. Nandakumar, "Highly active antiretroviral therapy induced adverse drug reactions in Indian human immunodeficiency virus positive patients," Pharmacy Practice, vol. 9, no. 1, pp. 48-55, 2011.

[20] R. R. Modayil, A. Harugeri, G. Parthasarathi et al., "Adverse drug reactions to antiretroviral therapy (ART): An experience of spontaneous reporting and intensive monitoring from ART centre in India," Pharmacoepidemiology and Drug Safety, vol. 19, no. 3, pp. 247-255, 2010.

[21] F. Weldegebreal, H. Mitiku, and Z. Teklemariam, "Magnitude of adverse drug reaction and associated factors among hivinfected adults on antiretroviral therapy in hiwot fana specialized university hospital, Eastern Ethiopia," Pan African Medical Journal, vol. 24, article no. 255, 2016.

[22] W. T. Tadesse, A. B. Mekonnen, W. H. Tesfaye, and Y. T. Tadesse, "Self-reported adverse drug reactions and their influence on highly active antiretroviral therapy in HIV infected patients: a cross sectional study," BMC Pharmacology \& Toxicology, pp. 1532, 2014.

[23] B. Dibaba and M. Hussein, "Factors Associated with NonAdherence to Antiretroviral Therapy among Adults living with HIV/AIDS in Arsi Zone, Oromia," Journal of AIDS \& Clinical Research, vol. 08, no. 01, 2017.

[24] G. Teklay, B. Legesse, and M. Legesse, "Adverse Effects and Regimen Switch among Patients on Antiretroviral Treatment in a Resource Limited Setting in Ethiopia," Journal of Pharmacovigilance, vol. 01, no. 04, p. 115, 2013.

[25] M. Asrat et al., "Prevalence and Associated Factors of Art Adverse Effect among PLWH on Art in Debre Markose Referal Hospital, North East Ethiopia, 2013," Family Medicine \& Medical Science Research, vol. 03, no. 03, 2014.

[26] R. Kyajja, J. K. Muliira, and E. Ayebare, "Personal coping strategies for managing the side effects of antiretroviral therapy among patients at an HIV/AIDS clinic in Uganda," African Journal of AIDS Research, vol. 9, no. 3, pp. 205-211, 2011.

[27] M. Lorío, J. Colasanti, S. Moreira, G. Gutierrez, and C. Quant, "Adverse drug reactions to antiretroviral therapy in HIVinfected patients at the largest public hospital in Nicaragua," Journal of the International Association of Providers of AIDS Care, vol. 13, no. 5, pp. 466-470, 2014.

[28] G. Quatremère, M. Guiguet, P. Girardi et al., "How are women living with HIV in France coping with their perceived side effects of antiretroviral therapy? Results from the EVE study," PLoS ONE, vol. 12, no. 3, p. e0173338, 2017.

[29] K. A. Agu, A. C. Oparah, and U. M. Ochei, "Assessment of side effects coping practices of HIV-infected patients receiving antiretroviral therapy," Pharmacoepidemiology and Drug Safety, vol. 21, no. 12, pp. 1302-1310, 2012.

[30] A. Jain, R. J. Lihite, M. Lahkar, and S. K. Baruah, "A study on adverse drug reactions to first-line antiretroviral therapy in HIV infected patients at a tertiary care hospital in Northeast India," HIV \& AIDS Review, vol. 15, no. 4, pp. 131-135, 2016.

[31] E. Mûnene and B. Ekman, "Association between patient engagement in HIV care and antiretroviral therapy medication adherence: Cross-sectional evidence from a regional HIV care center in Kenya," AIDS Care Psychological and Socio-medical Aspects of AIDS/HIV, vol. 27, no. 3, pp. 378-386, 2015.

[32] G. R. Pennap, U. Abdullahi, and I. A. Bako, "Adherence to highly active antiretroviral therapy and its challenges in people living with human immunodeficiency virus (HIV) infection in Keff," Nigeria. Journal of AIDS and HIV Research, vol. 5, no. 2, pp. 5228, 2013. 




The Scientific World Journal
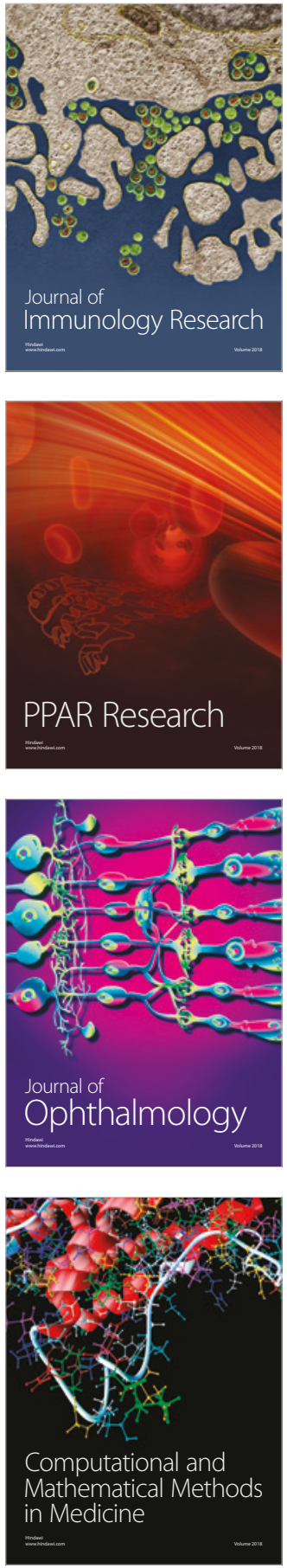

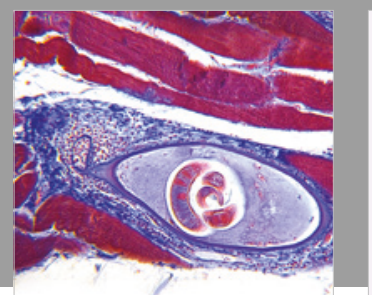

Gastroenterology Research and Practice



\section{Hindawi}

Submit your manuscripts at

www.hindawi.com
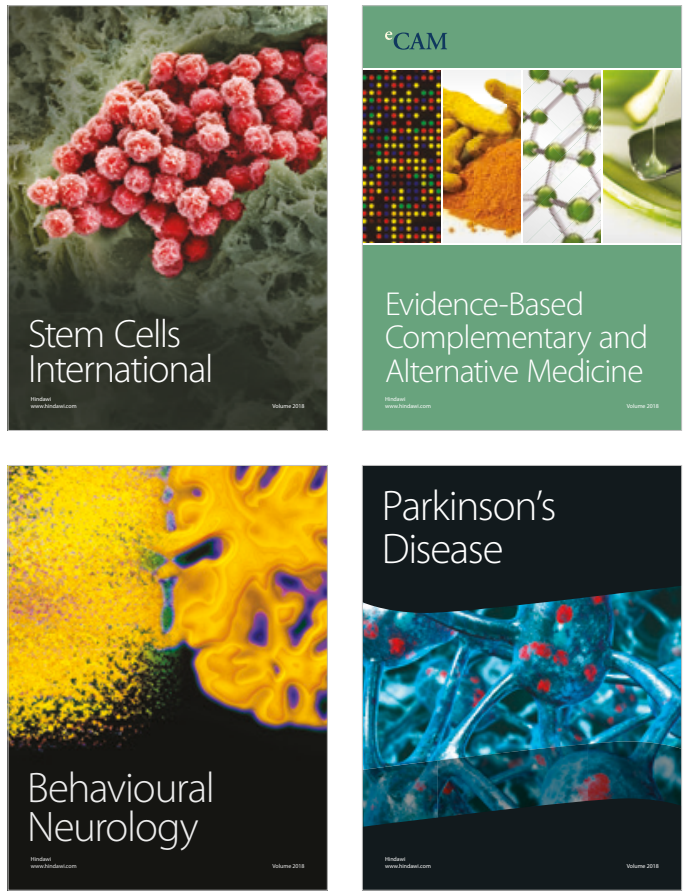

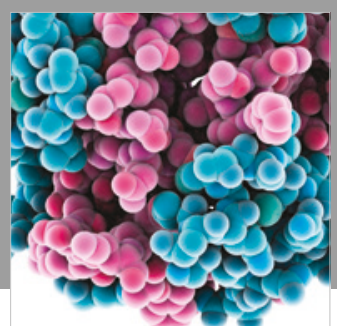

ournal of

Diabetes Research

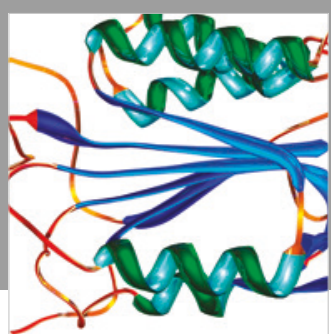

Disease Markers
